\title{
The influence of trait and induced state impulsivity on food intake in normal-weight healthy women
}

Citation for published version (APA):

Guerrieri, R., Nederkoorn, C., Stankiewicz, K., Alberts, H. J. E. M., Geschwind, N., Martijn, C., \& Jansen, A. T. M. (2007). The influence of trait and induced state impulsivity on food intake in normal-weight healthy women. Appetite, 49, 66-73. https://doi.org/10.1016/j.appet.2006.11.008

Document status and date:

Published: 01/01/2007

DOI:

10.1016/j.appet.2006.11.008

Document Version:

Publisher's PDF, also known as Version of record

Document license:

Taverne

\section{Please check the document version of this publication:}

- A submitted manuscript is the version of the article upon submission and before peer-review. There can be important differences between the submitted version and the official published version of record.

People interested in the research are advised to contact the author for the final version of the publication, or visit the DOI to the publisher's website.

- The final author version and the galley proof are versions of the publication after peer review.

- The final published version features the final layout of the paper including the volume, issue and page numbers.

Link to publication

\footnotetext{
General rights rights.

- You may freely distribute the URL identifying the publication in the public portal. please follow below link for the End User Agreement:

www.umlib.nl/taverne-license

Take down policy

If you believe that this document breaches copyright please contact us at:

repository@maastrichtuniversity.nl

providing details and we will investigate your claim.
}

Copyright and moral rights for the publications made accessible in the public portal are retained by the authors and/or other copyright owners and it is a condition of accessing publications that users recognise and abide by the legal requirements associated with these

- Users may download and print one copy of any publication from the public portal for the purpose of private study or research.

- You may not further distribute the material or use it for any profit-making activity or commercial gain

If the publication is distributed under the terms of Article $25 \mathrm{fa}$ of the Dutch Copyright Act, indicated by the "Taverne" license above, 


\title{
The influence of trait and induced state impulsivity on food intake in normal-weight healthy women
}

\author{
Ramona Guerrieri*, Chantal Nederkoorn, Kasia Stankiewicz, Hugo Alberts, \\ Nicole Geschwind, Carolien Martijn, Anita Jansen \\ Department of Experimental Psychology, Maastricht University, P.O. Box 616, 6200 MD Maastricht, The Netherlands
}

Received 20 September 2006; received in revised form 27 November 2006; accepted 30 November 2006

\begin{abstract}
Previous research has linked overeating and overweight/obesity to impulsivity. To find out whether impulsivity causes overeating and hence overweight and obesity, we attempted to prime the concept of impulsivity in healthy participants. In a within-subjects design one sample participated in two conditions. In both conditions participants did a priming task that either hinted subtly at the concept of impulsivity or that was neutral in content. Each time the priming task was followed by a bogus taste test. Trait impulsivity was measured by means of a behavioural task and self-report. Firstly, we hypothesized that participants would eat more during the taste test after they had been primed with the concept "impulsivity" compared to after the control session. Secondly, we expected that a more impulsive personality would predict a heightened food intake. Thirdly, we expected that impulsivity would predict food intake better than restraint. The results showed that both the self-report measure of impulsivity and the behavioural task predicted food intake. Restraint did not significantly predict food intake. Primed impulsivity did not increase food intake, possibly because the priming effect did not last long enough.
\end{abstract}

(C) 2007 Elsevier Ltd. All rights reserved.

Keywords: Impulsiveness; Inhibitory control; Priming; Food intake

\section{Introduction}

The World Health Organization (WHO) has declared obesity a global epidemic (WHO, 2003). This epidemic brings with it a rise in chronic diseases like diabetes and cancers (Hu, 2003). Quality of life from a psychological and social point of view is in many cases also seriously affected (Karlsson, Taft, Sjöström, Torgerson, \& Sullivan, 2003). Besides the physical, psychological and social consequences for the individual, there are the financial consequences for society. In the United States an estimated $9 \%$ of medical expenditures are attributable to overweight and obesity (Flegal, 2005). It is clear that something needs to be done to stop and even reverse this obesity epidemic. For this reason much research has been done on causal and maintaining factors of obesity. Genetic, biological, psy-

\footnotetext{
${ }^{*}$ Corresponding author.

E-mail address: r.guerrieri@psychology.unimaas.nl (R. Guerrieri).
}

chological and sociocultural factors have been suggested (Drewnowski, 1991).

One such psychological factor is impulsivity. Generally impulsivity is defined as the tendency to think, control and plan insufficiently. In most cases this results in an inaccurate or maladaptive response (Solanto et al., 2001). Impulsivity is considered a multidimensional construct (Wingrove \& Bond, 1997) for two reasons. First, correlations between self-report measures and behavioural measures of impulsivity are generally weak. This could mean that self-report impulsiveness questionnaires measure a different aspect of impulsivity than behavioural impulsivity tasks do. Second, even within the behavioural tasks different operationalizations and explanatory models of impulsivity are used and these often intercorrelate poorly.

Roughly, one could say that there are three main aspects of impulsivity. The first is impulsiveness, defined as "acting on the spur of the moment without being aware of any risk involved" (Eysenck, Eating, \& Pearson, 1984, p. 315) and 
measured by self-report. The second is response inhibition, which is predominantly measured by behavioural tasks. Barkley (1997) suggests that inhibitory control is necessary for executive functions such as self-regulation. If response inhibition is disturbed, then the very first self-regulatory act of inhibiting the prepotent response already fails, with all its consequences. The third aspect of impulsivity is sensitivity to reward, which is measured both by behavioural tasks and by self-report questionnaires. People who are sensitive to reward detect more rewarding stimuli and are more likely to approach these rewarding stimuli (Avila, 2001). It should be noted that impulsiveness and response inhibition, but not reward sensitivity, are the focus of the current study.

One can imagine that all three aspects of impulsivity contribute to the obesity epidemic (Davis, Levitan, Smith, Tweed, \& Curtis, 2006). First, when one often acts on the spur of the moment, momentary craving might be more important than future goals of losing weight. Second, when one is confronted with palatable food, the prepotent response is to eat it. In times when food was scarce this was an adaptive response (Blundell \& Gillett, 2001). However, it is feasible that in today's obesogenic environment not being able to inhibit one's prepotent responses contributes significantly to the problem of obesity. Third, sensitivity to reward might lead people make the wrong food choices: they might prefer foods that are sweet and fat because palatable food has a greater rewarding value than bland food (Davis et al., 2007).

Research has begun to demonstrate a link between overeating and impulsivity, measured with self-report, with response inhibition tasks and with sensitivity to reward tasks. Nasser, Gluck, and Geliebter (2004) have shown that Binge Eating Disorder (BED) patients score significantly higher on a self-report measure of general impulsiveness compared to controls. They also found positive significant correlations $(\sim 0.50)$ between participants' impulsivity score and the BED criteria "Loss of control during a binge" and "Eating when not physically hungry". Nederkoorn, Braet, Van Eijs, Tanghe, and Jansen (2006) found that obese children were impaired in general response inhibition as measured by the stop-signal paradigm compared to control participants. In other words, even on a very basic motoric level that has nothing to do with food the obese children were less able to inhibit their responses. Moreover, impulsivity turned out to be an obstacle in the treatment of the obese children: the children that were worst at inhibiting responses, lost less weight (Nederkoorn, Braet, et al., 2006; Nederkoorn, Jansen, Mulkens, \& Jansen, in press).

Nederkoorn, Braet, et al. (2006) also found that the obese children were more sensitive to reward during a behavioural task compared to control children. Other research has shown that obese children have difficulties with delay of gratification tasks only when the incentive is edible (Bonato \& Boland, 1983). This suggests that food could be especially rewarding for the obese. This has indeed been found. In a study by Saelens and Epstein (1996) obese participants chose to work for food instead of sedentary activities more often than controls. In sum, overweight and obese people seem more sensitive to reward and less adequate at the inhibition of prepotent responses, especially when it comes to resisting palatable food.

Recently it has been shown that even in healthy, lean participants impulsivity is of importance when it comes to food. Healthy individuals who are more sensitive to reward according to a self-report questionnaire turned out to have more pronounced neural responses to images of appetizing food (Beaver et al., 2006). This could indicate that for highimpulsive people it is harder to resist food than for lowimpulsive people. Indeed, Guerrieri, Nederkoorn, and Jansen (2007) found that high-impulsive women ate more during a bogus taste test than their low-impulsive peers when impulsivity was measured by self-report, but not by the stop-signal paradigm. The high-impulsive women also scored significantly higher on the Eating Disorders Examination Questionnaire (EDE-Q; Fairburn \& Beglin, 1994). This indicates that the high-impulsives exhibited more "eating disordered" cognitions and behaviours compared to the low-impulsives, although the clinical cut-off scores for eating disorders were not reached.

In conclusion, impulsivity in all its forms has repeatedly been linked to overweight and obesity. Although there are exceptions (see Guerrieri et al., 2007) impulsivity seems to be linked to reactions to palatable food, to "eating disordered" cognitions and to overeating in healthy participants. The relationship between increased impulsivity and the problem of overeating is quite robust since it generally persists even when impulsivity is measured in different ways (self-report versus behavioural tasks; response inhibition versus sensitivity to reward). However, based on previous research one cannot draw conclusions on causality. The studies that have been conducted are mostly of a correlational or quasi-experimental nature. This makes it impossible to rule out a third variable that influences impulsivity as well as overeating. If one wishes to conclude that impulsivity causes a heightened food intake, one needs to manipulate impulsivity experimentally. One should randomly assign healthy subjects to one of two groups: an experimental group in which impulsivity is manipulated experimentally versus a control group. If the experimental group shows a heightened food intake during a bogus taste test, then one could rightfully conclude that increased impulsivity caused the heightened food intake. We could find only one study in which similar methodology was used. Rotenberg et al. (2005) primed "lack of control" thoughts and these thoughts did indeed lead to greater food intake compared to priming "control" thoughts. This suggests that impulsivity, which shows overlap with the construct of "lack of control", might indeed promote overeating in a sample of healthy participants. However, no neutral condition was included, so it is not clear whether "control" cognitions led to less 
food intake, whether "lack of control" cognitions led to increased food intake, or both.

Because of the importance of this type of experimental research, which is the only way to investigate the causal relation between impulsivity and overeating, we tried to generalize the results of Rotenberg et al. (2005). We included a neutral control condition to avoid the issues in the Rotenberg study. We attempted to manipulate impulse control experimentally by means of a priming task that differed from the task that Rotenberg et al. (2005) used. Priming is a frequently used method in social cognition research. It is applied to enhance the cognitive availability of a psychological construct. Research has shown that priming procedures affect people's judgments and behaviour (Bargh, Gollwitzer, Lee-Chai, Barndollar, \& Trötschel, 2001; Higgins, Rholes, \& Jones, 1977). In the current study priming was used to manipulate the accessibility of the impulsivity construct in the hope that this priming would affect eating behaviour. In a withinsubjects design one sample participated in two conditions. In both conditions participants did priming task that either hinted subtly at the concept of impulsivity or that was neutral in content. After the priming task participants did a bogus taste test in both conditions. Trait impulsivity was measured by means of a behavioural task and self-report.

We hypothesized that participants would eat more during the taste test after they had been primed with the concept "impulsivity" compared to after the control session. In light of the findings of Guerrieri et al. (2007) it was also expected that a more impulsive personality would predict a heightened food intake. It is possible that trait impulsivity interacts with the priming task. In other words, high-impulsive people could react differently to the priming of impulsivity compared to low-impulsive people. However, we had no specific expectations concerning the presence of this interaction or its specific form.

Restraint (Herman \& Polivy, 1980) or the extent to which people diet (mostly without success) and worry about their weight, is another important variable to consider when looking at eating behaviour. It has been shown repeatedly that, compared to unrestrained eaters, restrained eaters consume more food after having consumed a high-caloric preload. This is called "counterregulation" (Herman \& Polivy, 1980). This counterregulation is thought to occur because the consumption of the preload acts as a disinhibitor: it removes inhibitions and eliminates restraint. It turned out that it is not even necessary to consume food in order to disinhibit restrained eaters. Mere exposure to food stimuli is sufficient to break down dietary restraint (Jansen \& van den Hout, 1991; Rogers and Hill, 1989). In other studies participants who were identified as restrained eaters were found to eat more than unrestrained eaters when they were given ad libitum access to palatable food, not preceded by a preload or cue exposure (e.g., Jansen, 1996). Moreover, Nederkoorn, Van Eijs, and Jansen (2004) found that restrained eaters were worse at prepotent response inhibition, i. e. more impulsive, compared to controls. In combining these findings we can conclude that the heightened food intake in restrained eaters may be a consequence of their increased impulsivity. Hence, we hypothesized that in the current study impulsivity would predict food intake better than restraint.

In sum, we had three hypotheses: (a) participants will eat more during the taste test after they have been primed with the concept "impulsivity" compared to after the control session, (b) a more impulsive personality will predict a heightened food intake, (c) impulsivity will predict food intake better than restraint. Moreover, we explored whether trait impulsivity would interact with the priming of impulsivity.

\section{Methods}

\section{Participants}

Forty-two normal-weight female students were recruited to participate in a study on "taste perception". Four participants were excluded because they missed one or more sessions. This left us with 38 participants (mean age: $19.3 \pm 1.3$ years; mean BMI: $22.2 \pm 2.9$ ). They received course credit or a monetary reward for their participation. All participants were debriefed by e-mail.

\section{Materials}

The Scrambled Sentences Task (Srull \& Wyer, 1979) is a priming method that originates from social psychology. To our knowledge, this priming task has never been used to prime impulsivity, but is has already been used successfully to prime control (Araya, Akrami, Ekehammar, \& Hedlund, 2002). It is believed that a schema associated with a certain trait will be activated when one is exposed to behavioural examples of this trait. Unobtrusive exposure to behavioural examples of a trait is attained as follows. Participants receive five words in a randomized order. It is their task to construct a grammatically correct sentence with four out of five given words. This task exposes the participants to the intended content while it averts their attention from the contents to the syntax of the sentences (Kühnen \& Hannover, 2000). In the current study participants constructed 25 sentences per session. They were only required to say the unscrambled sentences out loud. This saved considerable time compared to letting participants write down the unscrambled sentences. During the experimental session fifteen sentences hinted subtly at the concept of impulsivity (e.g. Patrick lets himself go) and ten sentences served as fillers (e.g. Donald reads the paper). During the control session participants constructed 25 sentences that were neutral in content. It should be noted that sentences that had anything to do with food were avoided.

The Barratt Impulsiveness Scale (BIS; Patton, Stanford, \& Barratt, 1995) is a self-report questionnaire that 
measures trait impulsiveness. It consists of 30 items to be rated on a 4-point scale. Scores range from 30 to 120 with higher scores indicating more impulsiveness. The BIS consists of three subscales: motor impulsiveness (acting without thinking), attentional impulsiveness (not focusing on the task at hand, cognitive instability) and nonplanning impulsiveness (lack of orientation to the future).

The $I_{7}$ Impulsiveness Questionnaire ( $I_{7}$; Eysenck, Pearson, Easting, \& Allsopp, 1985) is a 54-item self-report questionnaire that aims to measure trait impulsiveness, venturesomeness and empathy. Scores range from 0 to 54 with higher scores indicating more impulsiveness.

The Stop Signal Paradigm (Logan, Schachar, \& Tannock, 1997) is based on the notion that impulsive behaviour can be operationalized as a diminished ability to inhibit prepotent responses. In order to measure inhibitory control a behavioural computer task was developed (Logan et al., 1997). This computer task contains two sorts of trials: go trials $(75 \%)$ and stop trials $(25 \%)$. During the go trials the participant performs a choice reaction time task: the participant learns to press a certain button as fast as possible dependent on the stimulus that is presented (an $\mathrm{X}$ on the right or an $\mathrm{O}$ on the left for $1500 \mathrm{~ms}$ ). This learned response has to be inhibited during the stop trials: a tone serves as a stop signal and tells the participant not to push the button in response to the stimulus. At the start of the task the delay between the go signal ( $\mathrm{X}$ or $\mathrm{O}$ ) and the stop signal is set to $250 \mathrm{~ms}$. A tracking procedure adapts the delay dynamically depending on the participant's behaviour. If the participant inhibits successfully, the task is made more difficult by increasing the delay by $50 \mathrm{~ms}$. In the case of an unsuccessful inhibition the delay decreased by $50 \mathrm{~ms}$, making the task easier. The task consists of four blocks of 64 trials each and a practice block of ten trials. Two variables are measured: reaction time (RT) and stop delay. The stop signal reaction time (SSRT), the main independent variable, is calculated by subtracting the stop delay from the reaction time (Logan et al., 1997). The longer the SSRT, the more impulsive a participant is thought to be.

The Restraint Scale (RS; Herman \& Polivy, 1980) collects information on attitudes towards weight, degree and frequency of dieting, loss of control over eating and weight fluctuations. Scores range from 0 to 40 .

In order to measure food intake, participants took part in three bogus taste tests using three milkshakes $(260 \mathrm{~g} /$ $420 \mathrm{kcal} /$ milkshake) per taste test. The milkshakes were vanilla flavour during the first session and strawberry flavour during the second and the third session. About ten minutes before the arrival of the participant we prepared the milkshakes by mixing $100 \mathrm{ml}$ of whole milk with $150 \mathrm{~g}$ of ice cream with whipped cream in a milkshake machine. Strawberry flavour was added to the milkshakes that were used during the second and third session. The participants were asked to taste three milkshakes and to fill in a Taste Test Questionnaire. Participants had to rate the milkshakes on creaminess, sweetness and overall palatability. They also had to fill in a number of open-ended questions on the taste and mouth feel of the milkshakes. Moreover, the participants had to indicate which of the three milkshakes had a slightly different taste compared to the other two. This was all done to give the participants a chance to consume the milkshakes. The data from this questionnaire were not analysed, except for three items that measured how much participants felt like tasting the shakes (ranging from 1: "not at all" to 5: "very much") and how strong their intentions were to drink the milkshakes and to buy the milkshakes (ranging from 1: "not strong at all" to 5: "very strong").

Mood and hunger measurements were taken in order to rule out pre-existing differences in hunger and mood between the neutral and experimental session. At the beginning of each session hunger and mood was measured on a five-point scale that ranged from "not at all" (1) to "very" (5). The moods that were measured were: happy, sad, anxious, nervous, relaxed, angry, disappointed, and energetic. In order to rule out participants who knew that we had tried to prime impulsivity or who were on to the true hypotheses of the study, a suspiciousness questionnaire was devised. Participants were asked to try to come up with a general theme for the sentences that they had constructed. Furthermore, participants had the opportunity to write down what they thought the true hypotheses of the study were. None of the participants named "impulsivity" or a linked theme and likewise none of the participants came close to the true hypotheses of the study.

\section{Procedure}

Participants had to complete four testing sessions: three individual sessions and one group session. For each participant the three individual sessions were planned on three consecutive days at approximately the same time of day. The group sessions were planned every three to four weeks.

The first individual session lasted approximately $40 \mathrm{~min}$. Participants started with the stop-signal task, followed by a taste test using three vanilla milkshakes. This taste test was done in order to give participants a chance to get used to eating in a laboratory situation. We knew from previous experience that participants exhibit a "neophobia effect" (Overduin \& Jansen, 1997; Roefs \& Jansen, 2004). This means that they eat far less when they have to eat in a lab for the first time compared to subsequent occasions. We did this first taste test to solve this problem.

During the second individual session, which lasted approximately $30 \mathrm{~min}$, participants filled in a general questionnaire that measured hunger and mood. This was followed by the Scrambled Sentences Task. Participants started with the experimental sentence task or the control sentence task, in a balanced order. After the sentence task participants did a taste test that was the same as the first one except for the use of strawberry milkshakes instead of vanilla milkshakes. 
The third individual session was the same as the second. Participants who did the experimental sentence task during the second session, did the control sentence task during this session and vice versa. The same flavour (strawberry) was used during the taste test. After filling in the suspiciousness questionnaire, participants were weighed and measured.

The last session, the group session, served to let the participants fill in the questionnaires that measured impulsivity and restraint: the $I_{7}$, the BIS and the RS. It lasted approximately $20 \mathrm{~min}$.

\section{Results}

\section{Pre-existing differences and neophobia effect}

Paired-samples $t$-tests indicated that there were no preexisting differences in hunger and mood between the neutral and the experimental session (see Table 1). We did find a neophobia effect: a within-subjects ANOVA indicated that at least one session differed from the remaining sessions as far as food intake was concerned, $F(2,74)=8.28, p<0.01$. Post-hoc analyses with Bonferroni correction ( $\alpha$ divided by 3: $\alpha=0.017$ ) indicated that the food intake during session 1 was significantly lower compared to session $2, t(37)=2.82, p<0.017$ and 3 , $t(37)=3.55, p<0.017$. The difference between session 2 and 3 was not significant, $t(37)=1.65, p>0.1$. The mean food intake was $119 \mathrm{~g}$ (SD $74 \mathrm{~g}$ ) for session $1,152 \mathrm{~g}$ (SD $94 \mathrm{~g}$ ) for session 2 and $174 \mathrm{~g}$ (SD $114 \mathrm{~g}$ ) for session 3.

Hypothesis 1. Participants will eat more during the taste test after they have been primed with the concept "impulsivity" compared to after the control session

A paired-samples $t$-test indicated that food intake during the experimental and control condition did not differ significantly. Intention to drink and buy the milkshakes also did not differ significantly. However, during the experimental session participants felt more like tasting the milkshakes compared to the control session (see Table 2 for descriptives, test statistics and significance levels). Order effects were tested and were not significant, $F(1,36)=2.7$, $p>0.1$.

Hypotheses 2 and 3. A more impulsive personality will predict a heightened food intake and impulsivity will predict food intake better than restraint.

Because BIS and $I_{7}$ scores correlated significantly, $r=0.41, p<0.05$, both scores were standardized and then averaged to result in one self-report score for impulsiveness (Self-Report Impulsiveness). The Stop Signal Reaction Time (SSRT) served as the behavioural measure of impulsivity (Behavioural Impulsivity). These measures were included in a correlation matrix (see Table 3), together with Total Food Intake and the Restraint Scale (RS). Only the correlation between Behavioural Impulsivity and Total Food Intake was significant. The correlation between Behavioural Impulsivity and Self-report Impulsiveness was not significant, so both measures could be included as predictors in the linear regression analysis.

Both impulsivity measures and the RS scores were centred and used as predictors in a multivariate linear regression analysis with Total Food Intake (sum of session 1,2 and 3) as the dependent variable. This model was significant, $r^{2}=0.25, F(3,34)=3.7, p<0.05$. Behavioural Impulsivity proved to be a significant predictor of Total Food Intake, $\beta=0.33, t(37)=2.15, p<0.05$, and Selfreport Impulsiveness was a marginally significant predictor of food intake, $\beta=0.29, t(37)=1.91, p<0.1$. However, RS did not predict Total Food Intake, $\beta=0.21$, $t(37)=1.35, p>0.1$.

Removing the nonsignificant predictor led to a more significant model, $r^{2}=0.21, F(2,35)=4.54, p<0.02$, in which both Self-report Impulsiveness, $\beta=0.32$, $t(37)=2.08, \quad p<0.05$, and Behavioural Impulsivity, $\beta=0.38, t(37)=2.46, p<0.02$, proved to be significant predictors of total food intake.

Table 1

Hunger and mood measurements at the beginning of the neutral and experimental session, measured on a five-point scale ranging from "not at all" (1) to "very" (5)

\begin{tabular}{|c|c|c|c|c|c|c|}
\hline & \multicolumn{2}{|c|}{ Neutral session } & \multicolumn{2}{|c|}{ Experimental session } & \multicolumn{2}{|c|}{ For difference $\mathrm{N}-\mathrm{E}$} \\
\hline Hungry & 2.95 & 1.14 & 3.00 & 1.04 & -0.24 & 0.81 \\
\hline $\mathrm{Sad}$ & 1.39 & 0.79 & 1.29 & 0.73 & 0.94 & 0.35 \\
\hline Anxious & 1.21 & 0.57 & 1.08 & 0.27 & 1.40 & 0.17 \\
\hline Nervous & 1.34 & 0.78 & 1.47 & 0.76 & -1.09 & 0.28 \\
\hline Disappointed & 1.26 & 0.72 & 1.18 & 0.39 & 0.68 & 0.50 \\
\hline Energetic & 3.18 & 0.93 & 3.24 & 0.88 & -0.32 & 0.75 \\
\hline
\end{tabular}

Note: $\mathrm{N}-\mathrm{E}=$ mood scores obtained during the experimental session were subtracted from the mood scores obtained during the neutral session. 
Table 2

Differences between the neutral versus the experimental session for food intake, and 3 taste test questions, measured on a five-point scale ranging from "not strong at all" (1) to "very strongly" (5)

\begin{tabular}{|c|c|c|c|c|c|c|}
\hline & \multicolumn{2}{|c|}{ Neutral session } & \multicolumn{2}{|c|}{ Experimental session } & \multicolumn{2}{|c|}{ For difference $\mathrm{N}-\mathrm{E}$} \\
\hline How much do you feel like tasting the milkshakes? & 2.74 & 1.37 & 3.18 & 1.06 & -2.01 & 0.05 \\
\hline Intention to drink these milkshakes & 2.43 & 1.26 & 2.51 & 1.33 & -0.68 & 0.50 \\
\hline \multirow{2}{*}{ Intention to buy these milkshakes } & 1.55 & 1.39 & 1.50 & 1.35 & & \\
\hline & 0.40 & 0.69 & & & & \\
\hline
\end{tabular}

Note: $\mathrm{N}-\mathrm{E}=$ mood scores obtained during the experimental session were subtracted from the mood scores obtained during the neutral session.

Table 3

Pearson product-moment correlations between total food intake, the selfreport measurement of impulsiveness (self-report impulsiveness), the behavioural measurement of impulsivity (behavioural impulsivity), and the restraint scale $(\mathrm{RS})$

\begin{tabular}{llll}
\hline & $\begin{array}{l}\text { Total food } \\
\text { intake }\end{array}$ & $\begin{array}{l}\text { Self-report } \\
\text { impulsiveness }\end{array}$ & $\begin{array}{l}\text { Behavioural } \\
\text { impulsivity }\end{array}$ \\
\hline $\begin{array}{l}\text { Self-report } \\
\text { impulsiveness }\end{array}$ & 0.26 & - & \\
$\begin{array}{l}\text { Behavioural } \\
\text { impulsivity }\end{array}$ & $0.33^{\mathrm{a}}$ & -0.14 & - \\
RS & 0.30 & 0.10 & 0.20 \\
\hline
\end{tabular}

${ }^{\mathrm{a} C}$ Correlation is significant at the 0.05 level (two-tailed).

Table 4

Mean food intakes (g) and standard errors for interaction effects between trait and state impulsivity

\begin{tabular}{llll}
\hline Trait impulsivity & State impulsivity & $M$ & SE \\
\hline Self-report & & & \\
Low-impulsives & Neutral priming task & 146 & 25 \\
& Impulsive priming task & 131 & 19 \\
High-impulsives & Neutral priming task & 201 & 28 \\
& Impulsive priming task & 192 & 21 \\
Behavioural & & & \\
Low-impulsives & Neutral priming task & 135 & 26 \\
& Impulsive priming task & 141 & 21 \\
High-impulsives & Neutral priming task & 188 & 26 \\
& Impulsive priming task & 169 & 21 \\
\hline
\end{tabular}

\section{Exploration: Interaction between state and trait impulsivity}

A 2 (neutral versus experimental condition; WS) by 2 (low versus high impulsives; BS) mixed model ANOVA showed that there was no significant interaction between state and trait impulsivity both when trait impulsivity was measured by the stop-signal task, $F(1,36)=2.40 ; p>0.1$, and by self-report, $F(1,36)=0.25 ; p>0.6$. See Table 4 for descriptives.

\section{Discussion}

In accordance with our previous study (Guerrieri et al., 2007) we found that trait impulsivity predicts heightened food intake in normal-weight healthy women. This was the case for both measures of impulsivity: self-report and behavioural. The low correlation between both sorts of measures has been found in other studies (Wingrove \& Bond, 1997) and it might indicate that self-report and behavioural measures of impulsivity measure different aspects of impulsivity in motor, cognitive, social and emotional domains (Solanto et al., 2001). Another reason for the low correlation might lie in the qualitative differences between self-report and behavioural measures (Enticott, Ogloff, \& Bradshaw, 2006). On the one hand, self-report measures are sensitive to a person's biases and inaccuracies whereas behavioural measures are considered to be more objective. On the other hand, the environment in which laboratory tasks are administered might be too neutral whereas the items of self-report measures usually refer to real-life situations.

In the current study both measures of impulsivity predict food intake. This result supports the possibility that impulsive people overeat more easily. Because of this they might be more prone to develop overweight or even obesity. This might also explain why overweight and obese people have been found to be more impulsive and why obesity has been linked to $\mathrm{AD} / \mathrm{HD}$, a disorder that is hallmarked by an excess of impulsive behaviour (Davis et al., 2006). Disproportionate amounts of children with $\mathrm{AD} / \mathrm{HD}$ were found within a group of children who were hospitalized for severe obesity (Agranad-Meged et al., 2005). The reverse also turned out to be true: the mean $\mathrm{BMI}$ in a sample of $\mathrm{AD} / \mathrm{HD}$ boys was significantly higher than the age-adapted reference values (Holtkamp et al., 2004).

As hypothesized, impulsivity scores predicted food intake better than Restraint. The nonsignificant correlation between RS and impulsivity and RS and food intake does not support the theory that impulsivity mediates the effect of Restraint on food intake. It is possible that this is only the case when Restraint scores are extreme. Nederkoorn 
et al. (2004), who found that highly restrained participants were worse at prepotent response inhibition, i. e. more impulsive, selected their participants on the basis of RS scores $(<6$ and $>15)$. This resulted in more extreme groups. With a mean of 11.5 and a standard deviation of 4.8 Restraint scores were not at all extreme in the current sample.

Despite an effect of trait impulsivity on food intake we were not able to demonstrate that experimentally manipulated impulsivity affects the participants' food intake. In other words, we could not demonstrate that impulsivity causes heightened food intake. There are two possible reasons for not finding this effect. First, it is possible that the priming worked, but that state impulsivity does not influence food intake. Second, it can be that impulsivity does influence food intake, but that our manipulation was not strong enough, or did not last long enough to elicit an effect on food intake. In this case the latter option seems more likely: participants felt more like tasting the milkshakes immediately after the impulsive priming task compared to the control priming task. However, the intention to drink and to buy the milkshakes, items that were in the middle and at the end of the taste test questionnaire did not show this difference between the two sessions. This could indicate that there was an effect of priming, but that it only lasted for a very short period of time. In the study of Rotenberg et al. (2005) the priming task was presented as a memory task. The benefit is that participants had to keep the priming words in mind during the taste test. This enhances the probability of successful priming. In the current study the sentences that were constructed during the Scrambled Sentences Task did not have to be remembered until after the taste test. This might explain why the priming effect in this study was not strong enough to affect food intake. In future studies it might be wise to ensure that participants need to keep the priming words in mind until after the taste test. It has also been suggested that negative affect is needed for impulsive behaviour to occur (Fischer, Smith, \& Anderson, 2003). If this is the case, future-priming studies should not only aim to induce impulsivity, but also negative affect.

Ideally one would use a state measure of impulsivity as a manipulation check when trying to induce impulsivity. If participants score higher on this measure in the experimental condition compared to the control condition, then one is sure that the manipulation led to more food intake via increased impulsivity. However, using this kind of manipulation check was very difficult in the current study for two reasons. First, to our knowledge, a validated state measure of impulsivity does not exist. Second, the timing of the manipulation check is very difficult to determine. If one does the manipulation check immediately after the manipulation, one risk that the priming effect is already weakened once participants get to the taste test. If one does the check after the taste test, chances are that the manipulation did work during the taste test, but that the priming effect is too weak by the time participants get to the manipulation check. The timing problem could be resolved by conducting two studies: one study in which the manipulation is validated and a second study in which the effect of the manipulation on food intake is measured. However, the need for a validated state measure of impulsivity remains.

When inducing a state in order to establish a causal relationship between a trait and certain behaviours it is an issue whether the state that is induced is qualitatively comparable to the trait that it is supposed to represent. In other words, is the effect of being put in an "impulsive mood" comparable to the effect of having an impulsive personality? In the area of impulsivity little attention has been paid to this issue. More work has been done in the area of anxiety. Although trait and state anxiety are measured separately (Van der Ploeg, Defares, \& Spielberger, 1980), they are considered to be closely linked. The genes that influence state and trait anxiety are identical and people with high levels of trait anxiety are more likely to become state-anxious in reaction to a situation that is seen as threatening (Lau, Eley, \& Stevenson, 2006). If this reasoning also applies to impulsivity one could say that people with an impulsive personality are simply more prone to be in an impulsive mood. If it is indeed so that the effect of a trait on behaviour is mediated by its state, then it should not matter whether this state is induced or occurring naturally. However, further research is needed before this issue can be resolved.

Lastly, a methodological concern was that neophobia would occur. This means that participants need to get used to eating in the lab and consequently they eat far less the first time compared to a second and a third time. This is indeed what we found. If one has two experimental sessions this effect is not wanted because it would interfere with the experimental situation. That is why it is recommended that one lets participants eat in the lab once to let them get used to eating in this unnatural environment before one starts with experimental sessions.

In summary, the hypothesis that increased impulsivity causes a heightened food intake was not supported. The priming task that was used probably did not elicit a priming effect that was strong enough to affect food intake during the subsequent taste test. However, this study does show that in healthy, lean participants impulsivity, measured by both self-report and behavioural tasks, predicts food intake during bogus taste tests in the lab. In other words, the connection between impulsivity and food intake was supported. Further studies should concentrate on the induction of impulsivity in healthy subjects. This is the only way to establish whether increased impulsivity indeed causes a heightened food intake.

\section{References}

Agranad-Meged, A. N., Deitcher, C., Goldzweig, G., Leibenson, L., Stein, M., \& Galili-Weisstub, E. (2005). Childhood obesity and attention deficit/hyperactivity disorder: A newly described comorbidity in obese 
hospitalized children. International Journal of Eating Disorders, 37, $357-359$.

Araya, T., Akrami, N., Ekehammar, B., \& Hedlund, L. (2002). Reducing prejudice through priming of control-related words. Experimental Psychology, 49, 222-227.

Avila, C. (2001). Distinguishing BIS-mediated and BAS-mediated disinhibition mechanisms: A comparison of disinhibition models of Gray (1981, 1987) and of Patterson and Newman (1993). Journal of Personality and Social Psychology, 80, 311-324.

Bargh, J. A., Gollwitzer, P. M., Lee-Chai, A., Barndollar, K., \& Trötschel, R. (2001). The automated will: Nonconscious activation and pursuit of behavioral goals. Journal of Personality and Social Psychology, 81, 1014-1027.

Barkley, R. A. (1997). Behavioral inhibition, sustained attention, and executive functions: Constructing a unifying theory of ADHD. Psychological Bulletin, 121, 65-94.

Beaver, J. D., Lawrence, A. D., van Ditzhuijzen, J., Davis, M. H., Woods, A., \& Calder, A. J. (2006). Individual differences in reward drive predict neural responses to images of food. Journal of Neuroscience, 26, 5160-5166.

Blundell, J. E., \& Gillett, A. (2001). Control of food intake in the obese. Obesity Research, 9, 263S-270S.

Bonato, D. P., \& Boland, F. J. (1983). Delay of gratification in obese children. Addictive Behaviors, 8, 71-74.

Davis, C., Levitan, R. D., Smith, M., Tweed, S., \& Curtis, C. (2006). Associations among overeating, overweight, and attention deficit/ hyperactivity disorder: A structural equation modelling approach. Eating Behaviors, 7, 266-274.

Davis, C., Patte, K., Levitan, R., Reid, C., Tweed, S., \& Curtis, C. (2007). From motivation to behaviour: A model of reward sensitivity, overeating, and food preferences in the risk profile for obesity. Appetite, 48, 12-19.

Drewnowski, A. (1991). Obesity and eating disorders: Cognitive aspects of food preference and food aversion. Bulletin of the Psychonomic Society, 29, 261-264.

Enticott, P. G., Ogloff, J. R. P., \& Bradshaw, J. L. (2006). Associations between laboratory measures of executive inhibitory control and selfreported impulsivity. Personality and Individual Differences, 41, 285-294.

Eysenck, S. G. G., Eating, G., \& Pearson, P. R. (1984). Age norms for impulsiveness, venturesomeness and empathy in children. Personality and Individual Differences, 5, 315-321.

Eysenck, S. B. G., Pearson, P. R., Easting, G., \& Allsopp, J. F. (1985). Age norms for impulsiveness, venturesomeness and empathy in adults. Personality and Individual Differences, 6, 613-619.

Fairburn, C. G., \& Beglin, S. J. (1994). Assessment of eating disorders: Interview or self-report questionnaire? International Journal of Eating Disorders, 16, 363-370.

Fischer, S., Smith, G. T., \& Anderson, K. G. (2003). Clarifying the role of impulsivity in Bulimia Nervosa. International Journal of Eating Disorders, 33, 406-411.

Flegal, K. M. (2005). Epidemiologic aspects of overweight and obesity in the United States. Physiology and Behavior, 86, 599-602.

Guerrieri, R., Nederkoorn, C., \& Jansen, A. (2007). How impulsiveness and variety influence food intake in a sample of healthy women. Appetite, 45, 119-122.

Herman, C. P., \& Polivy, J. (1980). Restrained eating. In A. J. Stunkard (Ed.), Obesity (pp. 208-225). Philadelphia: Saunders.

Higgins, E. T., Rholes, W. S., \& Jones, C. R. (1977). Category accessibility and impression formation. Journal of Experimental Social Psychology, $13,141-157$.

Holtkamp, K., Konrad, K., Müller, B., Heussen, N., Herpertz, S., Herpertz-Dahlmann, B., et al. (2004). Overweight and obesity in children with attention deficit/hyperactivity disorder. International Journal of Obesity, 28, 685-689.

Hu, F. B. (2003). Overweight and obesity in women: Health risks and consequences. Journal of Women's Health, 12, 163-172.
Jansen, A., \& van den Hout, M. (1991). On being led into temptation: "Counterregulation" of dieters after smelling a "preload". Addictive Behaviors, 16, 247-253.

Jansen, A. (1996). How restrained eaters perceive the amount they eat. British Journal of Clinical Psychology, 35, 381-392.

Karlsson, J., Taft, C., Sjöström, L., Torgerson, J. S., \& Sullivan, M. (2003). Psychosocial functioning in the obese before and after weight reduction: Construct validity and responsiveness of the obesity-related Problems scale. International Journal of Obesity, 27, 617-630.

Kühnen, U., \& Hannover, B. (2000). Assimilation and contrast in social comparisons as a consequence of self-construal activation. European Journal of Social Psychology, 30, 799-811.

Lau, J. Y. F., Eley, T. C., \& Stevenson, J. (2006). Examining the state-trait anxiety relationship: A behavioural genetic approach. Journal of Abnormal Child Psychology, 34, 19-27.

Logan, G. D., Schachar, R. J., \& Tannock, R. (1997). Impulsivity and inhibitory control. Psychological Science, 8, 60-64.

Nasser, J. A., Gluck, M. E., \& Geliebter, A. (2004). Impulsivity and test meal intake in obese binge eating women. Appetite, 43, 303-307.

Nederkoorn, C., Van Eijs, Y., \& Jansen, A. (2004). Restrained eaters act on impulse. Personality and Individual Differences, 37, 1651-1658.

Nederkoorn, C., Braet, C., Van Eijs, Y., Tanghe, A., \& Jansen, A. (2006). Why obese children cannot resist food: The role of impulsivity. Eating Behaviors, 7, 315-322.

Nederkoorn, C., Jansen, E., Mulkens, S., \& Jansen, A. Impulsivity predicts treatment outcome in obese children. Behaviour Research and Therapy, in press.

Overduin, J., \& Jansen, A. (1997). Conditioned insulin and blood sugar responses in humans in relation to binge eating. Physiology and Behavior, 61, 569-575.

Patton, J. H., Stanford, M. S., \& Barratt, E. S. (1995). Factor structure of the barratt impulsiveness scale. Journal of Clinical Psychology, 51, 768-774.

Roefs, A., \& Jansen, A. (2004). The effects of information about fat content on food consumption in overweight/obese and lean people. Appetite, 43, 319-322.

Rogers, P. J., \& Hill, A. J. (1989). Breakdown of dietary restraint following mere exposure to food stimuli: Interrelationships between restraint, hunger, salivation, and food intake. Addictive Behaviors, 14, 387-397.

Rotenberg, K. J., Lancaster, C., Marsden, J., Pryce, S., Williams, J., \& Lattimore, P. (2005). Effects of priming thoughts about control on anxiety and food intake as moderated by dietary restraint. Appetite, 44, 235-241.

Saelens, B. E., \& Epstein, L. H. (1996). Reinforcing value of food in obese and non-obese women. Appetite, 27, 41-50.

Solanto, M. V., Abikoff, H., Sonuga-Barke, E., Schachar, R., Logan, G. D., Wigal, T., et al. (2001). The ecological validity of delay aversion and response inhibition as measures of impulsivity in $\mathrm{AD} / \mathrm{HD}$ : $\mathrm{A}$ supplement to the NIMH multimodal treatment study of $\mathrm{AD} / \mathrm{HD}$. Journal of Abnormal Child Psychology, 29, 215-228.

Srull, T. K., \& Wyer, R. S. (1979). The role of category accessibility in the interpretation of information about persons: Some determinants and implications. Journal of Personality and Social Psychology, 37, $1660-1672$.

Van der Ploeg, H. M., Defares, P. B., \& Spielberger, C. D. (1980). Handleiding bij de Zelf-Beoordelings Vragenlijst: Een Nederlandstalige bewerking van de Spielberger State-Trait Anxiety Inventory [A manual for the Self-Assessment Questionnaire: A Dutch version of the Spielberger State-Trait Anxiety Inventory]. Swets \& Zeitlinger b.v., Lisse.

WHO. (2003). Obesity and overweight. World Health Organization.

Wingrove, J., \& Bond, A. J. (1997). Impulsivity: a state as well as a trait variable. Does mood awareness explain low correlations between trait and behavioural measures of impulsivity? Personality and Individual Differences, 22, 333-339. 